\title{
Comparative Study of the Oral Health Profile of Institutionalized Elderly Persons in Brazil and Barcelona, Spain
}

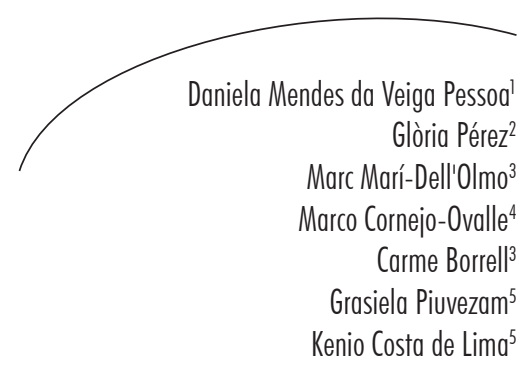

Abstract

Objective: To compare the oral health profile of institutionalized elderly persons in Brazil and in Barcelona, Spain, by gender and country of residence. Methods: A cross-sectional study was performed of individuals aged 65 years and above $(n=1,440)$, resident in the health region of Barcelona and in Brazil. Two surveys and exams relating to the oral health status of institutionalized elderly persons in Brazil (in 2008) and in Barcelona, Spain (in 2009) were carried out. Periodontal disease, tooth loss and dental caries were analyzed, considering age and cognitive ability. The sample was stratified by gender and country. Bivariate and multivariate Robust Poisson Regression models were used to obtain adjusted Prevalence Ratios (aPR), and a 95\% confidence interval (95\% CI) was employed. Results: In Barcelona, men and women had a higher prevalence of periodontal illness: Men - calculus (aPR:1.5; CI:1.08-2.19) and pocket (aPR:2.05; CI:1.43-2.93) results. Women - calculus (aPR:2.4; CI:1.77-3.24) and pocket (aPR:3.2; CI:2.29-4.53) results. In Barcelona there was a lower prevalence of edentulism (aPR:0.49; CI:0.37-0.65) and functional edentulism (aPR:0.49; CI:0.40-0.60) among men. The same results were found among women with a lower prevalence of edentulism (aPR:0.49; CI: 0.41-0.58) and functional edentulism (aPR:0.42; CI: 0.30-0.49). Conclusions: A poor state of oral health of men and women was observed in both countries, with the elderly from Barcelona having worse periodontal health and the elderly from Brazil having greater tooth loss.

\footnotetext{
Universidade do Estado do Rio Grande do Norte, Departamento de Odontologia. Caicó, Rio Grande do Norte, Brasil.

2 Agència de Salut Pública de Barcelona. Centro de Investigación Biomédica en Red (CIBER) Epidemiología y Salud Pública (CIBERESP). Barcelona, Espanha.

3 Centro de Investigación Biomédica en Red (CIBER) Epidemiología y Salud Pública (CIBERESP). Agència de Salut Pública de Barcelona, Espanha.

4 Universitdade do Chile, Facultdade de Odontologia. Santiago, Chile. Agència de Salut Pública de Barcelona. Barcelona, Espanha.

5 Universidade Federal do Rio Grande do Norte (UFRN), Departamento de Saúde Coletiva. Natal, Rio Grande do Norte, Brasil.

Keywords: Older People. Oral Health. Health of Institutionalized Elderly. 


\section{INTRODUCTION}

The global population of elderly people will grow in coming years, particularly in developing countries. In Brazil, the population aged 65\% and over will reach forty eight million by 2050 , representing $22.7 \%$ of the population. ${ }^{1}$ In Europe, the growth of the population of older people has occurred gradually. Some population projections show that the elderly population in Spain will reach $28 \%$ of the population by $2040 .^{2}$

Due to the aging population, health authorities throughout the world are facing growing demand for improved health care, including with regard to health problems caused by oral disease. ${ }^{3}$ Therefore, improvement of the oral health of older people has become a priority for the Global Oral Health Program of the WHO (World Health Organization) ${ }^{4}$

Both oral health and oral healthcare vary between countries and between regions of the same country. ${ }^{5}$ In Spain, where the National Health Service provides universal healthcare, dental services exclude restoration and focus on extraction and revision. ${ }^{6}$ In the Autonomous Region of Catalonia, whose capital is the city of Barcelona, dental programs emphasize the child population and people with disabilities (only groups to have access to restorative procedures) and the actions of fluoridated mouthwashes are reduced to primary schools. ${ }^{7}$ In this context, the elderly population is jettisoned public dental care.

The Brazilian National Health Service provides basic level, specialized, universal health care to the population. However, only $37 \%$ of the population has access to this service. ${ }^{8}$ Regarding elderly Brazilians, it was observed that among the dentate, the use of dental services was $26.6 \%$ and among edentulous, $10.4 \%$, indicating that the use of dental services was lower among those who needed them most. ${ }^{9}$ In order to broaden the inclusion of oral health in the SUS, was launched in 2004, the
National Oral Health Policy (PNSB) - "Smiling Brazil". ${ }^{10}$ Although among its assumptions are the qualification of primary health care and ensuring the integrity of the shares, the same as in Spain, the political "Smiling Brazil", also not intended oral health practices specific to the elderly. These facts bring consequences for oral health of this population group.

The physical and social effects of poor oral health in older people has been observed, such as decreased chewing performance, limited food choice, weight loss, malnutrition, communication problems, low self-esteem and well-being, and a negative manner of interacting with ordinary life. ${ }^{3,11}$ Aesthetics dissatisfaction is directly linked to the absence of teeth and is essential to trigger negative feelings of self-esteem among individuals, taking effect on social relations. ${ }^{12}$

With respect to institutionalized older people, literature shows that geriatric syndromes are associated with the risk of admission to long-stay institutions. ${ }^{13}$ Therefore, institutionalized older people represent the most vulnerable group due to their increased frailty, having a worse state of health than non-institutionalized older people. This situation is made worse by the lack of health care in the institutions. ${ }^{14}$ A number of health studies have shown how the oral health of institutionalized older people is characterized by high tooth loss, lack of regular preventative care for specific oral problems, and lack of dental treatment. ${ }^{15-17}$ In this context, the availability of data regarding the oral health status of institutionalized older people from different countries is essential for monitoring oral health, ${ }^{4}$ in addition to indicating specific actions aimed at improving the quality of life of these people. Therefore, the aim of this study was to compare the oral health profile of elderly people aged 65 and older, living in long-stay institutions in Brazil and Barcelona, Spain, in 2008 and 2009, respectively, according to gender and country residence with the purpose of understanding the different realities. 


\section{METHODS}

They were followed the criteria established by Strobe in the preparation of this manuscript. This study does not intend to compare the data on a national basis but compare the realities within the long-stay institutions for the elderly in both countries.

A cross-sectional study of institutionalized older people aged 65 years and above in the health regions of Barcelona, Spain and Brazil in 2009 and 2008, respectively, was performed. Data was taken from two surveys and a clinical examination of the oral health conditions of the individuals. The design of these surveys has been previously described ${ }^{18-20}$ however, a summary is provided below.

The selection of sample survey of seniors from Brazilian long-stay institution, in 2008, was based on the population of elderly people living in public and private institutions of eleven municipalities of medium and large population size, chosen randomly and belonging to each of the five geographical regions. The cities of each region were randomly selected from the following criteria: 1) municipalities with more than 100,000 inhabitants with a population greater than or equal the median age found in each geographical region; 2) institutions legally registered. A total of 1,412 individuals were selected of which 1,192 (84.4\%) participated in the survey. Individuals younger than 65 years were excluded from the present study. The total number of Brazilian older people included was 1,018 .

In 2009, in the Barcelona health region in Spain, there were 1,300 people aged 65 or more with a residential profile (i.e. waiting to be moved to one of the 46 public or subsidized long-stay centers). Of these, two centers declined to participate in the study. The convenience sample included people aged 65 and over in 25 long-stay centers which could be accessed during fieldwork. A total of 422 people were included. ${ }^{20}$
Finally, the population included in the study was 1,440 people aged 65 years or above.

The study undertaken in Brazil was approved by the Ethics Research Committee of the Federal University of Rio Grande do Norte (protocol no. 0033.0.051.000-06). The study performed in Barcelona, Spain, was approved by the Clinical Ethics Committee of the Instituto Municipal d'Assistència Sanitària (Barcelona, Spain) (IMAS) (protocol no. 2008/3666/I).

The oral examinations of the individuals included in the study were performed in accordance with WHO methodology. ${ }^{21}$

In Brazil, data collection was performed by five calibrated dentists with Kappa values of between 0.71 and 0.89. In Barcelona, Spain, a single dentist performed data collection with intra-examiner Kappa values between 0.85 and 1.00 .

The dependent variables were: 1) Use of upper denture (use of some form of denture in the upper arch - yes/no); 2) use of lower denture (use of some form of denture in the lower arch - yes/no); 3) necessity of upper denture (necessity of some form of denture in the upper arch - yes/no); 4), necessity of lower denture (necessity of some type of denture in the lower arch -yes/no); 5) edentulism (total absence of natural teeth - yes/no): 6) functional edentulism (existence of less than twenty teeth yes/no); 7) Community Periodontal Index (CPI) categorized as: CPI calculus (sextant of the mouth whose worst condition was the presence of calculus for each individual -yes/no), CPI pocket (sextant of mouth whose worst periodontal condition was the presence of surface or deep pockets for each individual-yes/no), CPI Excluded Sextant (older people with all sextants excluded).$^{18}$ The CPI was not characterized as a bleeding on probing CPI because of the low number for this category.

The independent variables were: 1) age: as a continuous variable in years, 2) cognitive capacity: appropriate cognitive conditions, according to medical diagnosis - yes/no. ${ }^{19,20}$ 
Descriptive analysis of all variables was performed. Bivariate and multivariate Poisson Robust Regression models were used to obtain crude Prevalence Ratios (cPR) and adjusted Prevalence Ratios (aPR) and their respective 95\% Confidence Intervals $(95 \% \mathrm{CI})$. In the multivariate model, all the variables with $p<0.05$ in bivariate analysis were included in the regression model, like other conceptually plausible variables. ${ }^{20}$ Therefore the adjustment variables were age and cognitive capacity.

\section{RESULTS}

There were more women than men in the surveys from both countries $57.3 \%$ in Brazil and $68 \%$ in Barcelona, Spain. The mean age of older people in Barcelona was older than that in Brazil (Table 2). In terms of oral health, there was more damage caused by caries among participants in
Brazil, where median values for DMFT, number of teeth lost, edentulism and functional edentulism were significantly higher than Spain. With respect to oral health rehabilitation, elderly individuals in Brazil used more upper dentures and had more necessity for lower dentures than elderly individuals in Barcelona, Spain. Periodontal disease was more prevalent among elderly individuals in Barcelona, Spain (Table 1).

In the multivariate model (Table 3), it was observed that men from Barcelona, Spain had a higher prevalence of dental calculus and periodontal pockets and lower prevalence of partial and total tooth loss than men in Brazil. Women in Barcelona, Spain had a higher prevalence of necessity for upper dentures, presence of dental calculus and periodontal pockets and lower prevalence of use of upper, partial tooth loss and total tooth loss than women in Brazil. 
Table 1. Description of the oral health characteristics by categorical variables of institutionalized individuals aged 65 years or older stratified for sex and country of residence. Brazil, 2008; Barcelona, Spain, 2009.

\begin{tabular}{|c|c|c|c|c|c|c|c|c|c|c|c|}
\hline \multirow{5}{*}{ Categorical Variables } & \multicolumn{11}{|c|}{ Sex } \\
\hline & \multirow{2}{*}{\multicolumn{6}{|c|}{$\begin{array}{c}\text { Men } \\
\text { Country }\end{array}$}} & \multirow{2}{*}{\multicolumn{5}{|c|}{$\begin{array}{l}\text { Women } \\
\text { Country }\end{array}$}} \\
\hline & & & & & & & & & & & \\
\hline & & \multicolumn{2}{|c|}{ Brazil } & \multicolumn{2}{|c|}{ Barcelona } & \multirow[b]{2}{*}{$\mathrm{p}^{*}$} & \multicolumn{2}{|c|}{ Brazil } & \multicolumn{2}{|c|}{ Barcelona } & \multirow[b]{2}{*}{$\mathrm{p}^{*}$} \\
\hline & & $\mathrm{n}$ & $\%$ & $\mathrm{n}$ & $\%$ & & $\mathrm{~N}$ & $\%$ & $\mathrm{n}$ & $\%$ & \\
\hline \multirow{2}{*}{$\begin{array}{l}\text { Use of Upper } \\
\text { Dentures }\end{array}$} & no & 315 & 71.8 & 102 & 76.7 & \multirow[t]{2}{*}{0.262} & 305 & 51.8 & 177 & 64.6 & \multirow[t]{2}{*}{$<0.001$} \\
\hline & yes & 124 & 28.2 & 31 & 23.3 & & 284 & 48.2 & 97 & 35.4 & \\
\hline \multirow{2}{*}{$\begin{array}{l}\text { Use of Lower } \\
\text { Dentures }\end{array}$} & no & 371 & 84.5 & 109 & 82.0 & \multirow[t]{2}{*}{0.482} & 427 & 72.5 & 208 & 75.9 & \multirow[t]{2}{*}{0.289} \\
\hline & yes & 68 & 15.5 & 24 & 18.0 & & 162 & 27.5 & 66 & 24.1 & \\
\hline \multirow{2}{*}{$\begin{array}{l}\text { Necessity of Upper } \\
\text { Dentures }\end{array}$} & no & 124 & 28.2 & 36 & 27.5 & \multirow[t]{2}{*}{0.864} & 279 & 47.4 & 98 & 36.6 & \multirow[t]{2}{*}{0.003} \\
\hline & yes & 315 & 71.8 & 95 & 72.5 & & 310 & 52.6 & 170 & 63.4 & \\
\hline \multirow{2}{*}{$\begin{array}{l}\text { Necessity of Lower } \\
\text { Dentures }\end{array}$} & no & 73 & 16.6 & 32 & 24.6 & \multirow[t]{2}{*}{0.039} & 159 & 27.0 & 80 & 29.9 & \multirow[t]{2}{*}{0.387} \\
\hline & yes & 366 & 83.4 & 98 & 75.4 & & 430 & 73.0 & 188 & 70.1 & \\
\hline \multirow[t]{2}{*}{ Edentulism } & no & 202 & 46.0 & 96 & 72.2 & \multirow[t]{2}{*}{$<0.001$} & 41 & 7.0 & 173 & 62.0 & \multirow[t]{2}{*}{$<0.001$} \\
\hline & yes & 237 & 54.0 & 37 & 27.8 & & 548 & 66.2 & 106 & 33.3 & \\
\hline \multirow{2}{*}{$\begin{array}{l}\text { Functional } \\
\text { Edentulism }\end{array}$} & no & 69 & 15.7 & 78 & 58.6 & \multirow[t]{2}{*}{$<0.001$} & 41 & 7.0 & 173 & 62.0 & \multirow[t]{2}{*}{$<0.001$} \\
\hline & yes & 370 & 84.3 & 55 & 41.4 & & 548 & 93.0 & 106 & 38.0 & \\
\hline \multirow[t]{2}{*}{ Calculus CPI } & no & 362 & 82.5 & 98 & 73.7 & \multirow[t]{2}{*}{0.025} & 519 & 88.1 & 206 & 73.8 & \multirow[t]{2}{*}{$<0.001$} \\
\hline & yes & 77 & 17.5 & 35 & 26.3 & & 70 & 11.9 & 73 & 26.2 & \\
\hline Pocket CPI & no & 376 & 85.6 & 97 & 72.9 & 0.001 & 540 & 91.7 & 205 & 73.5 & $<0.001$ \\
\hline & yes & 63 & 14.4 & 36 & 27.1 & & 49 & 8.3 & 74 & 26.5 & \\
\hline Excluded Sextant CPI & no & 161 & 36.7 & 76 & 57.1 & $<0.001$ & 138 & 23.4 & 158 & 56.6 & $<0.001$ \\
\hline & yes & 278 & 63.3 & 57 & 42.9 & & 451 & 76.6 & 121 & 43.4 & \\
\hline Cognitive Capacity & no & 210 & 47.8 & 76 & 57.1 & 0.060 & 325 & 55.2 & 145 & 51.2 & 0.274 \\
\hline & yes & 229 & 52.2 & 57 & 42.9 & & 264 & 44.8 & 138 & 48.8 & $<0.001$ \\
\hline
\end{tabular}

*Chi-square test with $95 \%$ level of significance 
Table 2. Description of the oral health characteristics and age by quantitative variables of institutionalized individuals aged 65 years or older stratified for sex and country of residence. Brazil, 2008; Barcelona, Spain, 2009.

\begin{tabular}{|c|c|c|c|c|c|c|c|}
\hline \multirow[b]{4}{*}{ Quantitative Variables } & \multicolumn{6}{|c|}{ Men } & \multirow{4}{*}{$\mathrm{p}^{*}$} \\
\hline & \multicolumn{3}{|c|}{ Brazil } & \multicolumn{3}{|c|}{ Barcelona } & \\
\hline & $\mathrm{n}$ & Median & P 25-P75 & $\mathrm{n}$ & Median & P 25-P75 & \\
\hline & & & & & & & \\
\hline DMFT Index & 439 & 32 & $27-32$ & 133 & 24 & $11-32$ & $<0.001$ \\
\hline Number of teeth with caries & 439 & 0 & $0-2$ & 133 & 1 & $0-4$ & 0.001 \\
\hline Number of filled teeth & 439 & 0 & $0-0$ & 133 & 0 & $0-0$ & 0.423 \\
\hline Number of missing teeth & 439 & 32 & $24-32$ & 133 & 27 & $20-32$ & 0.001 \\
\hline Number of teeth present & 439 & 0 & $0-8$ & 133 & 8 & $0-20$ & $<0.001$ \\
\hline \multirow[t]{3}{*}{ Age of Individual } & 439 & 77 & $71-83$ & 132 & 81 & $73-82$ & 0.006 \\
\hline & \multicolumn{5}{|c|}{ Women } & & \\
\hline & \multicolumn{3}{|c|}{ Brazil } & \multicolumn{2}{|c|}{ Barcelona } & & \\
\hline Quantitative Variables & $\mathrm{n}$ & Median & P 25-P75 & $\mathrm{n}$ & Median & P 25-P75 & $\mathrm{p}^{*}$ \\
\hline DMFT Index & 589 & 32 & $31-32$ & 279 & 25 & $12-32$ & $<0.001$ \\
\hline Number of teeth with caries & 589 & 0 & $0-0$ & 279 & 0 & $0-4$ & $<0.001$ \\
\hline Number of filled teeth & 589 & 0 & $0-0$ & 279 & 0 & $0-0$ & 0.569 \\
\hline Number of missing teeth & 589 & 32 & $29-32$ & 279 & 29 & $19-32$ & $<0.001$ \\
\hline Number of teeth present & 589 & 0 & $0-3$ & 279 & 7 & $0-20$ & $<0.001$ \\
\hline Age of Individual & 589 & 79 & $73-85$ & 278 & 83 & $76-87$ & $<0.001$ \\
\hline
\end{tabular}

*Mann-Whitney test with $95 \%$ level of significance 
Table 3. Prevalence Ratios of oral health conditions of institutionalized individuals aged 65 years or older according to sex in Brazil (2008) and Barcelona, Spain (2009).

\begin{tabular}{|c|c|c|c|c|c|c|c|}
\hline \multicolumn{8}{|c|}{ Men } \\
\hline \multirow[b]{2}{*}{ Variable Dependents } & \multicolumn{7}{|c|}{ Country (Reference Brazil) } \\
\hline & $\mathrm{n}$ & $\mathrm{cPR}^{*}$ & $95 \% \mathrm{CI}$ & $\mathrm{p}$ & aPR† & $95 \% \mathrm{CI}$ & $\mathrm{p}$ \\
\hline Use of Upper Dentures & 571 & 0.825 & $0.586-1.162$ & 0.271 & 0.860 & $0.615-1.202$ & 0.377 \\
\hline Use of Lower Dentures & 571 & 1.165 & $0.763-1.778$ & 0.479 & 1.211 & $0.793-1.851$ & 0.376 \\
\hline Necessity of Upper Dentures & 569 & 1.011 & $0.896-1.140$ & 0.863 & 0.996 & $0.883-1.124$ & 0.952 \\
\hline Necessity of Lower Dentures & 568 & 0.904 & $0.813-1.006$ & 0.064 & 0.898 & $0.806-1.001$ & 0.052 \\
\hline Edentulism & 571 & 0.515 & $0.387-0.687$ & $<0.001$ & 0.490 & $0.366-0.655$ & $<0.001$ \\
\hline Functional Edentulism & 571 & 0.491 & $0.399-0.603$ & $<0.001$ & 0.490 & $0.399-0.603$ & $<0.001$ \\
\hline Calculus CPI & 571 & 1.500 & $1.058-2.128$ & 0.023 & 1.541 & $1.084-2.191$ & 0.016 \\
\hline Pocket CPI & 571 & 1.886 & $1.315-2.705$ & 0.001 & 2.050 & $1.435-2.930$ & $<0.001$ \\
\hline \multirow[t]{3}{*}{ Excluded Sextant CPI } & 571 & 0.677 & $0.549-0.834$ & $<0.001$ & 0.653 & $0.530-0.805$ & $<0.001$ \\
\hline & \multicolumn{7}{|c|}{ Women } \\
\hline & \multicolumn{7}{|c|}{ Country (Reference Brazil) } \\
\hline Variable Dependents & $\mathrm{n}$ & $\mathrm{cPR}^{*}$ & $95 \% \mathrm{CI}$ & $p$ & aPR $†$ & $95 \% \mathrm{CI}$ & $p$ \\
\hline Use of Upper Dentures & 863 & 0.734 & $0.613-0.879$ & 0.001 & 0.699 & $0.586-0.835$ & $<0.001$ \\
\hline Use of Lower Dentures & 863 & 0.876 & $0.684-1.122$ & 0.294 & 0.793 & $0.620-1.014$ & 0.065 \\
\hline Necessity of Upper Dentures & 857 & 1.025 & $1.070-1.357$ & 0.002 & 1.237 & $1.101-1.390$ & $<0.001$ \\
\hline Necessity of Lower Dentures & 857 & 0.961 & $0.876-1.054$ & 0.397 & 0.989 & $0.903-1.084$ & 0.814 \\
\hline Edentulism & 868 & 0.503 & $0.422-0.600$ & $<0.001$ & 0.490 & $0.411-0.583$ & $<0.001$ \\
\hline Functional Edentulism & 868 & 0.408 & $0.351-0.475$ & $<0.001$ & 0.419 & $0.300-0.487$ & $<0.001$ \\
\hline Calculus CPI & 868 & 2.202 & $1.639-2.958$ & $<0.001$ & 2.396 & $1.774-3.236$ & $<0.001$ \\
\hline Pocket CPI & 868 & 3.188 & $2.288-4.442$ & $<0.001$ & 3.220 & $2.288-4.531$ & $<0.001$ \\
\hline Excluded Sextant CPI & 868 & 0.566 & $0.492-0.652$ & $<0.001$ & 0.554 & $0.482-0.638$ & $<0.001$ \\
\hline
\end{tabular}

*Crude Prevalence Ratio tPrevalence Ration adjusted for age and cognitive capacity 


\section{DISCUSSION}

The present study was the first to compare the oral health conditions of institutionalized individuals aged 65 years or older from Brazil and Barcelona, Spain. Brazil and Spain are countries with distinctly different aging patterns and dental care. In general, both male and female institutionalized older people in both countries have poor oral health conditions.

In both countries older men and older women had high levels of tooth loss. Institutionalization of older people is itself considered a risk factor for tooth loss, ${ }^{17}$ however it should be noted that the oral health of this population is a consequence of damage accumulated throughout life ${ }^{20}$ and reflects the model of dental health care adopted in both countries, which is characterized by limited access to dental care services and a fundamentally mutilative approach to dental care. ${ }^{20,22}$

Thus, it was verified that even tooth loss is a major public health problem in the countries investigated. This implies increased demand for oral health rehabilitation services for this population group. It was also observed that the highest prevalence of necessity of upper dentures is among women from Barcelona, Spain. This reveals the lack of rehabilitation among older women, which is also caused by the lack of public health policies aimed at the institutionalized population.

In the case of Brazil, the provision of dental health care is historically characterized by low complexity, mostly curative and mutilating, solutions of restricted access to the population. In the majority of municipalities, programs were conducted for school age children aged between 6-12 years, and pregnant women. Adults and the elderly only had access to emergency care units and mutilative treatment (23-26). This exclusive oral health care model existed in Brazil until 2004, when the country implemented the National Oral Health Policy entitled "Brazil Smiling" whereby individual and collective actions were implemented, aimed at the promotion, prevention, diagnosis, treatment and rehabilitation in primary and secondary levels of oral health care. ${ }^{27}$
Although there has been a gradual expansion of interventions in oral health policy, hegemonic models or private dentistry models focused on disease still prevail in Brazil. ${ }^{24}$ In a case study on the implementation process of the National Oral Health Policy - "Smiling Brazil" - in the municipalities of the Regional Health Department of Araraquara, São Paulo, Brazil, it was observed that the municipalities still find it difficult to deploy assumptions of "Smiling Brazil" because it was observed the tendency of maintaining the model centered on disease due to large pent-up demand, the charges with the production of procedures and training technicalities and clinical. ${ }^{25}$ It can therefore be stated that this new health policy has not had an effect on the older people in the present study, indicating the need for future studies to evaluate the impact of "Brazil Smiling" on this group.

In Spain, schoolchildren have the right to basic public dental care which is both preventative and restorative of permanent dentition, with restrictions. Each one of the 17 regions (Autonomous Communities) into which the country is divided, can provide these services in a different way, with public financing, and public and private delivery of the service. ${ }_{28}$ This model of provision of dental care is focused on promotion and prevention of oral disease in infant population, and centered on oral disease, instead of prevention and promotion of oral health among other age groups, which can also lead to inequalities, as the provision of such services is privately financed and only available to those who can afford it. Thus, oral health in Spain is the only area that does not have full coverage by the National Health System. The dental care for adults remains only palliative and rehabilitation of lost teeth due to oral disease is not covered, even partially subsidized, the health system. ${ }^{7}$

According to the present study, institutionalized older people from Barcelona, Spain have a higher prevalence of periodontal disease than those in Brazil. Among women, the prevalence of presence of calculus is double, and the prevalence of periodontal pocket is triple, the prevalence of the same in Brazil. This is caused by a greater presence of permanent teeth in older individuals in Barcelona, Spain, as there is a higher prevalence 
of edentulism and functional edentulism in Brazil. The presence of periodontal pockets can lead to infections, tooth mobility, cervical sensitivity and aesthetic changes, revealing the need for dental treatment for institutionalized older people and indicate a lack of oral care in long stay institutions for older people. Literature shows that carers do not provide adequate oral hygiene care for older residents, due to an absence of procedures, lack of knowledge of oral hygiene practices, and proper training. ${ }^{14}$

The present study has a number of limitations. It should be noted that the cross-sectional design does not allow analysis of the cause-effect relationship between the variables studied. Additionally, the limited number of explanatory variables common to both questionnaires justifies the absence of socioeconomic variables in the study. However, the dependent variables analyzed can explain the objective conditions of the oral health status of institutionalized older people in both countries. Other strength of the study is the comparison of the oral health status of institutionalized older people in two different social and economic environments, as well as of different dental care health systems.

\section{CONCLUSION}

The present study concludes that institutionalized older individuals aged 65 years and above resident in Brazil and Barcelona, Spain, had poor oral health, caused by a high prevalence of partial and total tooth loss in Brazil and periodontal disease in Barcelona. The results indicate that irrespective of the country studied, the oral health of institutionalized older people is vulnerable. Knowledge of this situation may assist with the reorientation of health policies aimed at this population, focused on the maintenance of oral health and improvements to quality of life.

\section{REFERENCES}

1. Instituto Brasileiro de Geografia e Estatística. Primeiros resultados definitivos do Censo 2010 [Internet]. Rio de Janeiro: IBGE; 2012 [acesso em 03 set 2012]. Disponível em: http://www.censo2010.ibge.gov.br.

2. Institut d'Estadística de Catalunya [Internet]. Catalunya: IDESCAT; 2012 [acesso em 6 set 2012]. Disponível em: http://www.idescat.cat/cat/poblacio/ poblestructura.html

3. Petersen PE, Kandelman D, Arpin S, Ogawa H. Global oral health of older people- call for public health action. Community Dent Health 2010;27(4 Suppl 2):257-67.

4. Petersen PE. Priorities for research for oral health in the 21st century: the approach of the WHO Global Oral Health Programme. Community Dent Health 2005;22(2):71-4.

5. Petersen PE, Yamamoto T. Improving the oral health of older people: the approach of the WHO Global Oral Health Programme. Community Dent Oral Epidemiol 2005;33(2):81-92.
6. Bravo M, Cortés J, Casals E, Llena C, AlmerichSilla JM, Cuenca E. Basic oral health goals for Spain 2015/2020. Int Dent J 2009;59:78-82.

7. Cortés M FJ, Cerviño FS, Blanco GJM, Simón S F. Informe sobre los Servicios de Salud Bucodental en España. Situación de las Comunidades Autónomas, 2013. RCOE, Rev Ilustre Cons Gen Col Odontól Estomatol Esp 2014;19(Supl. 1):12-42.

8. Bordin D, Fadel CB. Pact for health in Brazil: a descriptive analisys of the progression of oral health indicators. Rev Odontol UNESP 2012;41(5):305-11.

9. Martins AMEBL, Barreto SM, Pordeus IA. Uso de serviços odontológicos entre idosos brasileiros. Rev Panam Salud Pública 2007;22(5):308-16.

10. Brasil. Ministério da Saúde. Diretrizes da Política Nacional de Saúde Bucal [Internet]. Brasília, DF: 2004. [acesso em 12 Jul 2016]. Disponível em: http://189.28.128.100/dab/docs/publicacoes/geral/ diretrizes_da_politica_nacional_de_saude_bucal.pdf 
11. Gil-Montoya JA, Subirá C, Ramón JM, GonzálezMoles MA. Oral health- related quality of life and nutritional status. J Public Health Dent 2008; 68(2):88-93.

12. Moimaz SAS, De Almeida MEL, Lolli LF, Garbin CAS, Saliba NA. Envelhecimento: análise de dimensões relacionadas à percepção dos idosos. Rev Bras Geriatr Gerontol 2009;12(3):361-75.

13. Wang SY, Shamliyan TA, Talley KM, Ramakrishnan R, Kane RL. Not just specific diseases: systematic review of the association of geriatric syndromes with hospitalization or nursing home admission. Arch Gerontol Geriatr 2013;57(1):6-26.

14. Cornejo-Ovalle M, Costa -de-Lima K, Pérez G, Borrell C, Casals-Peidro E. Oral Health care activities performed by caregivers for institucionalized elderly in Barcelona-Spain. Med Oral Patol Oral Cir Bucal 2013;18(4):641-9.

15. World Health Organization. Oral health in aging societies: integration of oral health and general health: Report of a meeting convened at the WHO Centre for Health Developement in Kobe, Japan, 1-3 June 2005. Japan2005. Geneva: WHO; 2006.

16. Pizarro V, Ferrer M, Domingo-Salvany A, Benach J, Borrell C, Puigvert J, et al. Dental health differences by social class in home-dwelling seniors of Barcelona, Spain. J Public Health Dent 2006;66(4):288-91.

17. Eustaquio-Raga MV, Montiel-Company JM, Almerich-Silla JM. Factors associated with edentulousness in an elderly population in Valencia (Spain). Gac Sanit 2013;27(2):123-7.

18. Piuvezam G, De Lima KC. Factors associated with missing teeth in the Brazilian elderly institutionalised population. Gerodontology 2013;30(2):141-9.
19. Piuvezam G, De Lima KC. Self-perceived oral health status in institutionalized elderly in Brazil. Arch Gerontol Geriatr 2012;55(1):5-11.

20. Cornejo M, Perez G, De Lima KC, Casals-Peidro E, Borrell C. Oral Health-Related Quality of Life in institutionalized elderly in Barcelona (Spain). Med Oral Patol Oral Cir Bucal 2013;18(2):285-92.

21. World Health Organization. Oral Health surveys:basic methods. Geneve: WHO; 1998.

22. Islas-Granillo H, Borges-Yañes SA, Lucas-Rincón SE, Medina-Solís CE, Casanova-Rosado AJ, MárquezCorona ML, et al. Edentulism risk indicators among Mexican elders 60-year-old and older. Arch Gerontol Geriatr 2011;53(3):258-62.

23. Chaves SCL. Oral health in Brazil: the challenges for dental health care models. Braz Oral Res 2012;26:71-80.

24. Soares CLM. Constructing public oral health policies in Brazil: issues for reflection. Braz Oral Res 2012;26:94-102.

25. Aquilante AG, Aciole GG. Construindo um "Brasil Sorridente"?: Olhares sobre a implementação da Política Nacional de Saúde Bucal numa região de saúde do interior paulista. Cad Saúde Pública 2015;31(1):82-96.

26. Dutra CESV, Sanchez HF. Organização da atenção à saúde bucal prestada ao idoso nas equipes de saúde bucal da Estratégia Saúde da Família. Rev Bras Geriatr Gerontol 2015;18(1):179-88.

27. Pucca GA Junior, De Lucena EHG, Cawahisa PT. Financing national policy on oral health in Brazil in the context of the Unified Health System. Braz Oral Res 2010;24:26-32.

28. Widström E, Eaton KA. Oral healthcare systems in the extented European union. Oral Health Prev Dent 2004;2(3):155-94. 